\title{
Competition Indices of Intercropped Lupine (Local) and Small Cereals in Additive Series in West Gojam, North Western Ethiopia
}

\author{
Yayeh Bitew Bantie1, Fetien Abay Abera ${ }^{2}$, Tadesse Dessalegn Woldegiorgis ${ }^{3}$ \\ ${ }^{1}$ Adet Agricultural Research Centre, Institute of Amhara Agricultural Research, Bahir Dare, Ethiopia \\ ${ }^{2}$ Department of Plant Science, Mekelle University, Mekelle, Ethiopia \\ ${ }^{3}$ Department of Plant Science, Bahir Dar University, Bahir Dar, Ethiopia \\ Email: yayeh bitew@yahoo.com
}

Received 24 January 2014; revised 21 February 2014; accepted 1 April 2014

Copyright (C) 2014 by authors and Scientific Research Publishing Inc.

This work is licensed under the Creative Commons Attribution International License (CC BY).

http://creativecommons.org/licenses/by/4.0/

(c) (i) Open Access

\section{Abstract}

The experiment was conducted on intercropping of lupine (Lupinus albus L.) with wheat (Triticum aestivum), barley (Hordeum vulgar) and finger millet (Eleusine coracana) in 2009 at Adet Agricultural research station, in Western Gojam. The treatments were sole wheat at a seed rate of 175 $\mathrm{kg} / \mathrm{ha}$, sole barley at a seed rate of $125 \mathrm{~kg} / \mathrm{ha}$, sole finger millet at a seed rate of $30 \mathrm{~kg} / \mathrm{ha}$, sole lupine at a seed rate of $90 \mathrm{~kg} / \mathrm{ha}$, and an additive series of 25,50 and $75 \%$ of the sole lupine seed rate combined with the full cereal seed rate to determine the effect of intercropping on competition (CR) among the different species, the land equivalent and area time equivalent ratios (LER and ATER); and the economic feasibility of each intercropping system(MAI) as compared with sole cropped. The experimental design was a completely randomized block with nine intercropping and four sole cropping systems in three replications. Lupine was planted in rows after establishment of main crops. JMP-5 (SAS, 2002) software's was used to compute the analysis of variance. Partial LER of lupine was lower than LER of cereal, indicating an advantage for main crops and a disadvantage for the minor crop. Values of ATER showed $4.9 \%-31.3 \%$ and $11.1 \%-37.8 \%$ advantage in lupine-wheat and lupine-finger millet combinations, respectively, whilst lupine-barley combinations showed ATER of $54.5 \%-60.9 \%$ disadvantage. CR showed dominancy of wheat and barley over lupine while lupine was higher CR than finger millet. Positive MAI values were recorded in lupine-wheat and lupine-finger millet mixtures indicating that these intercropping systems were a definite yield advantage and the most profitable as compared to sole cropped. In conclusion, the lupine-finger millet mixture at the 50:100 seeding ratio and 75:100 seeding ratio; and lupine-wheat mixture at the 75:100 seeding ratio indicated a significant advantage from intercropping which was attributed to better MAI and land use efficiency (higher LER and ATER), lower CR and thereby enhanced sustainability of crop production in West Gojam, but the other socio- 
economic and cost of production aspects of intercropping should also be assessed especially under small scale farmers' conditions.

\title{
Keywords
}

\author{
Intercropping; Wheat; Barley; Finger Millet; Lupine; Seeding Ratio
}

\section{Introduction}

Intercropping is the cropping system involving the growth of two or more crops in the same piece of land at the same time or relayed which could compute for growth resources for certain growth period. It provides valuable ecosystem services such as improved pest control [1], increased resource use efficiency [2] in crop livestock mixed farming system. However, in many parts of Ethiopia, farmers traditionally harvest mainly once in a year on sole crop basis even in high rain fall areas. Moreover, in the past, many research efforts have been directed towards improving technology for sole cropping. Such traditional farming did not insure the production of adequate food for a family [3]. Different crops are grown traditionally in mixtures by small farmers to satisfy dietary needs, spread the period of peak demand for labor and minimize the risk associated with climate conditions [4]. Intercropping cereal with a legume, however, is relatively the most common in most parts of the country. Indeed, the traditional objective has been to produce a full yield of cereal (as much as with a sole crop) while the associated legume yield is considered as additional yield [4].

Lupine (Lupinus Spp.) is one of the major highland food legumes grown in Ethiopia. It is traditionally gown as intercrop with cereals and oil crops by low input farmers and is restricted to low-income classes, to times of drought [5]. Finger millet, wheat, and barley are the third, fourth and fifth stable cereal crops grown in west Gojam, respectively [6]. Farmers grow it as traditional additive system of intercropping in which lupine is used as minor crop and cereals as major crop. They grow it for the strategies to overcome the shortage of arable land and attribute several crops for diversification of crop products and for maintenance and improvement of soil fertility [7].

Moreover, lupine normally has greater growth duration than cereals, so that when grown together at the same time, cereals utilize resources earlier than lupine. Another possible explanation for such intercrop yield advantage is that the tape root system of lupine could exploit water and nutrients from deeper soil layers than cereals [5]. Therefore, this cropping system may help improve productivity of low external input farming or scarce in natural resources, unreliable rain fall and poor soil fertility.

However, management of lupine intercropped with cereal to maximize their complementarity and to minimize competition between them follows simple natural principles, and its practice is limited only by the imagination of farmers. Moreover, indices such as land equivalent ratio and area time equivalent ratio to describe precise assessment of the biological efficiency of the intercropping system [8], competitive ratio to define a measure of intercrop competition in intercropping systems [9] and monetary advantage index to evaluate economic advantage of each intercropping system as compared to sole cropping [10] were not used in intercropping systems of lupine with different cereals. Therefore, the objective of this paper is: 1) To determine the land use efficiency, competition ratio and to estimate the effect of competition among the different species used in nine intercropping systems, i.e., lupine with wheat, barley, and finger millet in three seeding ratios ( $25 \%, 50 \%$ and $75 \%$ of lupine with full cereal seed rates); 2) To examine the economic feasibility of these intercropping systems as compared to respective sole cropping.

\section{Materials and Methods}

\subsection{Description of the Study Area}

The study was conducted in the 2009 rain fed (main) cropping season at Adet Agricultural Research station (AARC), North Western Ethiopia. It is located between $11^{\circ} 17^{\prime} \mathrm{N}$ latitude and $37^{\circ} 43^{\prime} \mathrm{E}$ longitude with an altitude of 2240 masl [11]. The soil characteristics of experiment site were clay as shown Table 1.

The study area receives a uni-modal rainfall which extends early June to late September with regard to its 
Table 1. Physico-chemical properties of the soil in the lupine-cereal intercropping study at AARC in 2009/2010.

\begin{tabular}{|c|c|c|c|c|c|c|c|c|c|}
\hline \multicolumn{10}{|c|}{ Chemical and Mechanical Soil characteristics } \\
\hline \multirow{2}{*}{$\mathrm{PH}$} & \multirow{2}{*}{$\begin{array}{l}\text { OC } \\
(\%)\end{array}$} & \multirow{2}{*}{$\begin{array}{c}\text { Total } \\
\text { N (\%) }\end{array}$} & \multirow{2}{*}{$\begin{array}{l}\text { Av.P } \\
\text { ppm }\end{array}$} & \multirow{2}{*}{ CEC } & \multirow{2}{*}{ Ex.K } & \multicolumn{4}{|c|}{ Texture } \\
\hline & & & & & & Sand \% & Clay \% & Silt \% & Class \\
\hline 6.06 & 2.47 & 0.18 & 1.98 & 37.97 & 33.29 & 28 & 46.72 & 25.28 & Clay \\
\hline
\end{tabular}

Notes: CEC: Cation exchange capacity measured in cmol (+)/kg soil (NHAc), Av.P: Available phosphors in ppm, Ex.K: Exchangeable potassium (K) in $\mathrm{cmol}(+) / \mathrm{kg}$ soil (NHAc) and OC: organic carbon.

monthly distribution June, July and August are the three important months with high rain fall and more or less uniform spatial distribution [7]. The total annual rainfall of the current growing season was $975.3 \mathrm{~mm}$ which is less than the 23 year average total annual rainfall $(1253.4 \mathrm{~mm})$. The mean monthly minimum and maximum temperatures during the growing season were $11^{\circ} \mathrm{C}$ and $27.2^{\circ} \mathrm{C}$ which is greater than the 23 year average mean monthly minimum $\left(9.1^{\circ} \mathrm{C}\right)$ and maximum $\left(25.7^{\circ} \mathrm{C}\right)$ temperatures.

\subsection{Field Experimental Design}

Plots were laid out in randomized complete block design (RCBD) with three replications. The plot size was 12 $\mathrm{m}^{2}(2 \mathrm{~m} \times 6 \mathrm{~m})$ exclusive of the border area. There were nine intercropping and four sole cropping systems in additive series in the experiment.

\subsection{Test Materials and Series of Component Crop Proportion}

Additive series intercropping system was used, which is cropping of the base crop/cereals at optimum level and the addition of a proportion of the minor crop/lupine with the main crop being the one of primary importance because of economic or food production reasons. Thus, in the present study the added proportion of the minor crop ranged from $25 \%$ to $75 \%$ of its recommended plant population or seed rate, as shown in Table 2.

\subsection{Sowing Method and Management Practices}

The experiment was conducted in rain fed season. Pure stands of lupine, wheat, barley and finger millet as well as nine lupine-cereal mixtures in three seeding ratios in additive series (25\%, 50\% and 75\% of recommended lupine seed rate with full cereal seed rates) were planted. In sole cropping, lupine was planted in a plant population of 665000 plants/ha with an inter-row space of $30 \mathrm{~cm}$; and wheat, barley and finger millet were broadcasted at a seed rate of 175, 125 and $30 \mathrm{~kg} / \mathrm{ha}$. In the intercropping system, first lupine row was established in the inter-row spacing of 120, 66 and $35 \mathrm{~cm}$ for the 25\%, 50\% and 75\% seed proportion, respectively, and full cereal components were broadcasted between lupine rows on 4 July, 2009. For all cropping systems space between lupine plants were $5 \mathrm{~cm}$. Lupine was planted after establishments of main crops. All plots were received a basal application of Diammonium phosphate (DAP) $(18 \% \mathrm{~N}, 46 \% \mathrm{P})$ at the rate of $100 \mathrm{~kg} / \mathrm{ha}$ at planting. For cereal components, $100 \mathrm{~kg}$ nitrogen in the form of Urea $(46 \% \mathrm{~N})$ was applied except the sole lupine treatment assuming the lupine was benefit from self-fixed nitrogen. One third basal and two third top-dressed application of nitrogen were applied in the form Urea (46\% N) during planting time and at tillering stage of sole and intercropped cereals, respectively.

\subsection{Determination of Competition Indices and Monetary Advantages (Index)}

\subsubsection{Land Equivalent Ratio (LER)}

LER is used, as the criterion for mixed stand advantage as both lupine and cereal is desired species [8]. In particular, LER indicates the efficiency of intercropping for using the resources of the environment compared with monocropping [12]. The value of unity is the critical value. When the LER is greater than one, the intercropping favors the growth and yield of the species. In contrast, when LER is lower than one the intercropping negatively affects the growth and yield of the plants grown in mixtures [13]. It is an indicator of complementarity. The LER was calculated as [8].

$$
L E R=(L E R \text { Lupine }+L E R \text { Cereal }) ; \text { where, } L E R \text { Lupine }=\left(\frac{T L C}{Y I}\right) \text { and } L E R \text { Cereal }=\left(\frac{T L C}{Y C}\right)
$$


Table 2. Additive series of component crop production used in an experiment.

\begin{tabular}{ccccc}
\hline Treatment number & Crop species & Proportion $\%$ & Lupine $\%$ & Total population \\
\hline 1 & wheat & 100 & 0 & 100 \\
2 & wheat & 100 & 25 & 125 \\
3 & wheat & 100 & 50 & 150 \\
4 & wheat & 100 & 75 & 175 \\
5 & barley & 100 & 0 & 100 \\
6 & barley & 100 & 25 & 125 \\
7 & barley & 100 & 50 & 150 \\
8 & barley & 100 & 75 & 175 \\
9 & Finger millet & 100 & 0 & 100 \\
10 & Finger millet & 100 & 25 & 125 \\
11 & Finger millet & 100 & 50 & 175 \\
12 & Finger millet & 100 & 75 & 100 \\
\hline
\end{tabular}

Note: ${ }^{* *}$ cereals: wheat, barley and finger millet; and ${ }^{*}$ lupine.

where $Y_{\mathrm{L}}$ and $Y_{\mathrm{C}}$ were the yields of lupine and cereal, respectively, as sole crops and $Y_{\mathrm{Lc}}$ and $Y_{\mathrm{CL}}$ are the yields of lupine and cereal, respectively, as intercrops.

\subsubsection{Area Time Equivalent Ratio (ATER)}

ATER provides more realistic comparison of the yield advantage of intercropping over monocropping in terms of time taken by component crops in the intercropping systems than LER. ATER was calculated by formula developed by [14]:

$$
A T E R=\frac{(R Y \text { Cereal } \times T \text { Cereal })+(R Y \text { Lupine } \times T \text { Lupine })}{T}
$$

Where, RY cereal $=$ Relative yield of cereals in mixture, $\mathrm{T}$ cereal $=$ duration (in days) of cereals, $\mathrm{RY}$ lupine $=$ Relative yield of lupine in mixture, $\mathrm{T}$ lupine $=$ duration (in days) of lupine and $\mathrm{T}=$ Total duration of the intercropping system (in days). The interpretation of ATER involves that ATER > one implies yield advantage; ATER = one implies no effect of intercropping; ATER $<$ one shows yield disadvantages.

\subsubsection{Competitive Ratio (CR)}

Competitive ratio is used to assess competition between different species. The CR gives a better measure of competitive ability of the crops [9]. The CR represents simply the ratio of individual LERs of the two component crops and takes into account the proportion of the crops in which they are initially sown. It is indicators of competitiveness. The CR was calculated according to the following formula:

$$
\begin{aligned}
& C R=C R \text { Cereal- } C R \text { Lupine; } \\
& \text { where, } C R \text { Lupine }=\left(\frac{L E R \text { Lupine }}{L E R \text { Cereal }}\right) \times \frac{Z C L}{Z L C} \text { and } C R \text { Cereal }=\left(\frac{L E R \text { Cereal }}{L E R \text { Lupine }}\right) \times \frac{Z L C}{Z C L}
\end{aligned}
$$

where, ZLC is the sown proportion of lupine in mixture with cereal and ZCL the sown proportion of cereal in mixture with lupine. If CR > one, indicates the base crop is competitor, while values < one implies the minor component crop is profusely suppressed the base crop or if CR cereal $=0$, both crops are equally competitive, if CR cereal is positive then the cereal species is dominant, if CR cereal is negative then the cereal species is the dominated species.

\subsubsection{Monetary Advantage Index (MAI)}

It was also calculated to give some economic evaluation of intercropping as compared to sole cropping. The monetary advantage index (MAI) was calculated by the formula developed by [15]: 


$$
M A I=\frac{\text { (Value of Combined Intercrops }) \times(L E R-1)}{L E R}
$$

Since there is a high market price fluctuation, value of combined intercrops in each cropping system was the lowest prevailing market prices of each component crop in Ethiopian Birr per $/ \mathrm{kg}$ at the time of experiment. The lowest price at Adet district, Western Gojam after harvest of the crops was 2.80 birr $/ \mathrm{kg}$ for barely in November, 3.00 birr $/ \mathrm{kg}$ for wheat in November, 2.60 birr $/ \mathrm{kg}$ for finger millet in December [16] and $3.11 \mathrm{birr} / \mathrm{kg}$ for lupine in January. The higher the MAI value the more profitable is the cropping system [17].

\subsection{Data Analysis}

Data were statistically subjected to analysis of variance (ANOVA) using JMP-5 [18]. Combined analysis of variance was performed to determine LER, ATER, CR and MAI over three lupine-cereal combinations. In all the comparisons, the level of significance was set at $\alpha=0.05$. Mean comparison for the treatments were computed using each pair Tukey-HSD test for parameters found to be significantly different at a given level of significant.

\section{Results and Discussion}

\subsection{Land Equivalent Ratio (LER) and Area time Equivalent Ratio (ATER)}

\subsubsection{Land Equivalent Ratio (LER)}

In assessments of crop productivity of sole cropping systems, a useful expression is mass yield (mass per unit area). However, in intercropping systems, direct comparison is difficult because products are different for the different plant species growing on one piece of land [19]. In this case, crop productivity should be evaluated using a common unit. A widely used method is the land equivalent ratio (LER) [19]. Intercropping lupine with wheat, barley and finger millet in three seeding ratios significantly $(\mathrm{P}<0.05)$ affects the LER . The combined yield advantage in terms of total LER indices was greatest in the cases of lupine-wheat mixture at the 75:100 seeding ratio (1.49), followed by the same combination at the 25:100 seeding ratio (1.334) and at 50:100 seeding ratio (1.313) (Table 3). This indicates that $48.9 \%$ (0.48 ha), 33.38\% (0.33 ha) and 31.3\% (0.31 ha) more area would be required by a sole cropping system to equal the yield of intercropping system.

The second crop combination which gave higher total LER was lupine-finger millet at 75:100 seed ratio (1.294) followed by the same combination at 50:100 (1.234) and 25:100 (1.097) seeding ratios which causes, 29.41\%, 23.41\% and 9.68\% higher yield than sole cropping (Table 3). In these cases, total LER was significantly different from 1.00, which shows an advantage from intercropping over pure stands in lupine-wheat and lupine-finger millet combinations in terms of the use of environmental resources for plant growth [12]. These findings were in agreement with [20], who reported a mixed stand advantage at lower oat seeding proportions in common vetch-oat combination. Similarly, compared with corresponding sole crops, yield advantages have been recorded in pearl millet-cluster bean [21].

On the other hand, total LERs below 1.00 were found in all lupine- barley y combinations, which gave a disadvantage of these mixtures over pure stands (Table 3). This result was in agreement with [17] who reported that common vetch-barley and common vetch-triticale mixtures shows a disadvantage over pure stands. In most cases, the LER values were generally lower for intercropping systems involving barley and lupine than lupine and finger millet and wheat and lupine. This could be due to competitive ability of barely was higher than lupine. Similarly, LER values for lupine-finger millet combinations were less than lupine-wheat combinations probably due to finger millet and lupine as both crops had long growth duration and demanding resources at the same time as compared to wheat, which had contrasting maturity period.

\subsubsection{Area Time Equivalent Ratio (ATER)}

LER doesn't consider the duration of the crops in the field and it is based on the harvested products, and not on desired yield proportion of the component crops. Moreover, the choice of sole cropped yield for standardizing mixture yield in the estimation of LER is not clear [15]. Therefore, area time equivalent ratio (ATER) provides more realistic comparison of the yield advantage of intercropping over sole cropping in terms of variation in time taken by the component crops of different intercropping systems [14] [22].

Intercropping lupine with wheat, barley and finger millet in three seeding ratios significantly $(\mathrm{P}<0.05)$ affects the ATER. In all lupine-wheat and lupine-barley cropping systems, the ATER values were lesser than LER values 
Table 3. Area time equivalent ratios, partial and total land equivalent ratios of grain yield in lupine-cereal intercrops at three seeding ratios (additive series) at AARC, West Gojam in 2009.

\begin{tabular}{|c|c|c|c|c|}
\hline \multirow{3}{*}{ Treatments and statistics } & \multicolumn{4}{|c|}{ Mean } \\
\hline & \multicolumn{3}{|c|}{ Partial and total LER } & \multirow{2}{*}{ ATER } \\
\hline & Lupine & Cereal & Total & \\
\hline Sole lupine & $1.000^{\mathrm{a}}$ & - & $1.000^{\mathrm{bcd}}$ & $1.000^{\mathrm{ab}}$ \\
\hline Sole wheat & - & $0.990^{\mathrm{ab}}$ & $1.000^{\mathrm{bcd}}$ & $0.990^{\mathrm{b}}$ \\
\hline Sole barley & - & $1.000^{\mathrm{ab}}$ & $1.000^{\mathrm{bcd}}$ & $1.000^{\mathrm{ab}}$ \\
\hline Sole finger millet & - & $1.000^{\mathrm{ab}}$ & $1.000^{\mathrm{bcd}}$ & $1.000^{\mathrm{ab}}$ \\
\hline $25 \%$ Lupine $+100 \%$ wheat & $0.160^{\mathrm{e}}$ & $1.174^{\mathrm{a}}$ & $1.334^{\mathrm{ab}}$ & $1.049^{\mathrm{ab}}$ \\
\hline $50 \%$ Lupine $+100 \%$ wheat & $0.275^{\mathrm{e}}$ & $1.038^{\mathrm{ab}}$ & $1.313^{\mathrm{ab}}$ & $1.075^{\mathrm{ab}}$ \\
\hline $75 \%$ Lupine $+100 \%$ wheat & $0.546^{c}$ & $0.944^{\mathrm{ab}}$ & $1.489^{\mathrm{a}}$ & $1.313^{\mathrm{a}}$ \\
\hline $25 \%$ Lupine $+100 \%$ barley & $0.017^{\mathrm{f}}$ & $0.748^{\mathrm{b}}$ & $0.764^{\mathrm{d}}$ & $0.391^{\mathrm{c}}$ \\
\hline $50 \%$ Lupine $+100 \%$ barley & $0.021^{\mathrm{f}}$ & $0.765^{\mathrm{ab}}$ & $0.786^{\mathrm{d}}$ & $0.402^{\mathrm{c}}$ \\
\hline $75 \%$ Lupine $+100 \%$ barley & $0.024^{\mathrm{f}}$ & $0.868^{\mathrm{ab}}$ & $0.892^{\text {cd }}$ & $0.455^{\mathrm{c}}$ \\
\hline $25 \%$ Lupine $+100 \% \mathrm{f} /$ millet & $0.306^{\mathrm{d}}$ & $0.791^{\mathrm{ab}}$ & $1.097^{\mathrm{abc}}$ & $1.111^{\mathrm{ab}}$ \\
\hline $50 \%$ Lupine $+100 \% \mathrm{f} /$ millet & $0.512^{\mathrm{c}}$ & $0.813^{\mathrm{ab}}$ & $1.234^{\mathrm{abc}}$ & $1.378^{\mathrm{a}}$ \\
\hline $75 \%$ Lupine $+100 \% \mathrm{f} /$ millet & $0.635^{\mathrm{b}}$ & $0.659^{\mathrm{b}}$ & $1.294^{\mathrm{abc}}$ & $1.372^{\mathrm{a}}$ \\
\hline $\operatorname{LSD}(0.05)$ & 0.05 & 0.24 & 0.24 & 0.23 \\
\hline CV (\%) & 6.16 & 15.75 & 12.42 & 12.79 \\
\hline
\end{tabular}

Notes: Values (means) connected by different superscript letters are significantly $(\mathrm{P}<0.05)$ different within columns according to Tukey-HSD tests. ATER: Area time equivalent ratio; LER: Land equivalent ratio.

(Table 3) indicating the over estimation of resource utilization perhaps due to the wide variations in the maturity periods of the crops of which lupine stayed longer on the land and had enough time to compensate for the wheat competition. ATER is free from problems of over estimation of resource utilization contrary to LER. In contrast, in all lupine-finger millet cropping systems, the ATER values were higher than LER values indicating that absence of over estimation of resource utilization perhaps due to the narrow variations in the maturity periods of the crops (Table 3).

ATER values showed an advantage of $37.87 \%$ and $37.19 \%$ in lupine-finger millet combination at 50:100 and 75:100 seeding ratios, respectively and $31.34 \%$ in lupine-wheat at 75:100 seeding ratio followed by $11 \%$ in lupine-finger millet combination at 25:100 seeding ratios than the other mixtures and all sole cropped (Table 3). This could be due to the reason that intercropping systems can actually give more efficient total resource exploitation and greater overall production than sole crops (compatible intercrops) [23], optimum mixture ratios and staggered planting arrangements particularly planting dates. Similarly, compared with corresponding sole crops, yield advantages have been recorded in many non-legume-legume intercropping systems, including bean-wheat [2], groundnut-cereal fodders [17], barley-pea [24] and faba bean-barley [25].

Whereas, all lupine-barley intercropping showed values less than 1.00 and pure stands thus indicated the disadvantage. Lupine-barely intercropping resulted in 55\% - 61\% disadvantage with maximum disadvantage at 25:100 seeding ratio (61\%) with similar response to the other seeding ratios. This was in agreement with [26], who reported that intercropping reduced the yield of mustard-pea, mustard-lentil, and mustard-gram mixtures over sole-cropping. In other words the present experiment showed that the higher seeding ratio gave the highest yield advantage which was differ from what farmers currently used ( $\leq 25 \%$ lupine seed rate with full cereal seed rate).

\subsection{Competitive Ratio (CR) and Monitory Advantage Index (MAI)}

\subsubsection{Monitory Advantage Index (MAI)}

Substantial agronomic advantages from intercropping do not always ensure an economic advantage and there is a need for some economic evolutions and absolute yield comparisons of intercropping systems [27]. Thus, a more satisfactory use of monitory values would probably be to calculate the absolute value of the genuine yield advantage [15]. Accordingly, monitory advantage index (MAI) was calculated by multiplying the respective yields of the component crops by their lowest market prices during the experiment and divided by respective 
LER. Intercropping advantage values indicates the disadvantage of the system as the MAI values were in negative. On the other hand monetary advantage index values were positive which showed a definite yield advantage in intercropping compared to sole cropping [15]. It is an indicator of the economic feasibility of intercropping systems as compared to sole cropping [22].

MAI were significantly $(\mathrm{P}<0.01)$ influenced by intercropping lupine with wheat, barley and finger millet in three seeding ratios (Annex 9). The MAI values were positive under two intercropping systems in the present study, i.e. in all lupine-wheat and lupine-finger millet combinations (Table 4), which shows a definite yield advantage compared with the respective sole cropping systems tested in this study. The results of those combinations were similar to pearl millet-cluster beans intercrop [28] and wheat-rape intercrop [29]. MAI values in all lupine- barley combinations were found highly negative as compared to all pure stands due to very low LER caused by sever reduction in lupine yield. The result was in corroborates with [30] who reported that Vetchbarley intercropping in different seeding ratios gave negative MAI as compared to sole cropping. The lowest MAI of all pure stand crops also confirms farmers' justification of growing the lupine mainly as an intercrop with cereals.

Maximum negative value was recorded in lupine-barley combination at 25:100 (-2493.1) and 50:100 (-1147) seeding ratios followed by the same combination at 75:100 seeding ratio (-1539.3), implying the general unsuitability of lupine as an intercrop in all lupine-barley production systems and showed an economic disadvantage (Table 4). The combined maximum positive MAI values for intercrops were found in lupine-wheat combination at 75:100 seeding ratio (3489.2) and lupine-finger millet combination at 50:100 (2634) followed by lupine-finger millet combination at 75:100 (2425) seeding ratio and lupine-wheat combinations at 25:100 (2162.8) and 50:100 (2106.6) seeding ratios indicate that these intercropping systems had the highest economic advantage and implying the general suitability of lupine as an intercrop in lupine-wheat and lupine-finger millet production systems (Table 4). A plausible explanation for the later might be the better utilization of resources between lupine-wheat and lupine-finger millet combinations, the higher price of wheat and higher LER and lower CR value $(<1)$ (Table 4). These findings were also in agreement with the results of LER and the other competition indices (Table 3 and Table 4). Similarly, [17] found that when the LER were higher there is also significant economic benefit expressed with higher MAI.

Table 4. Competitive ratios and monitory advantage index for lupine-cereal intercrops at three seeding ratios (additive series) at AARC, West Gojam in 2009.

\begin{tabular}{|c|c|c|c|c|}
\hline \multirow{3}{*}{$\begin{array}{l}\text { Treatments and } \\
\text { statistics }\end{array}$} & \multicolumn{3}{|c|}{ Mean } & \multirow{3}{*}{ MAI } \\
\hline & \multicolumn{3}{|c|}{ Competitive ratio (CR) } & \\
\hline & CR lupine & CR cereal & CR total & \\
\hline Sole lupine & - & - & - & $-0.001^{\mathrm{abcd}}$ \\
\hline Sole wheat & - & - & - & $-60.000^{\mathrm{bcd}}$ \\
\hline Sole barely & - & - & - & $-0.067^{\mathrm{abcd}}$ \\
\hline Sole finger millet & - & - & - & $-0.001^{\mathrm{abcd}}$ \\
\hline $25 \%$ Lupine $+100 \%$ wheat & $0.55^{\text {bcd }}$ & $2.12^{d}$ & $1.58^{\mathrm{cd}}$ & $2162.8^{\mathrm{abc}}$ \\
\hline $50 \%$ Lupine $+100 \%$ wheat & $0.53^{\mathrm{cd}}$ & $1.96^{\mathrm{cd}}$ & $1.42^{\text {cd }}$ & $2106.6^{\mathrm{abc}}$ \\
\hline $75 \%$ Lupine $+100 \%$ wheat & $0.79^{\text {bcd }}$ & $1.30^{\text {cd }}$ & $0.52^{d}$ & $3489.2^{\mathrm{a}}$ \\
\hline $25 \%$ Lupine + 100\% barley & $0.09^{\mathrm{d}}$ & $13.20^{\mathrm{bc}}$ & $13.11^{\mathrm{bc}}$ & $-2493.1^{d}$ \\
\hline $50 \%$ Lupine + 100\% barley & $0.06^{\mathrm{d}}$ & $20.27^{\mathrm{ab}}$ & $20.21^{\mathrm{ab}}$ & $-2270.2^{\mathrm{d}}$ \\
\hline $75 \%$ Lupine + 100\% barley & $0.14^{\mathrm{d}}$ & $27.90^{\mathrm{a}}$ & $27.87^{\mathrm{a}}$ & $-1147.5^{\mathrm{cd}}$ \\
\hline $25 \%$ Lupine $+100 \%$ f/millet & $1.66^{\mathrm{a}}$ & $0.66^{\mathrm{d}}$ & $-1.00^{\mathrm{d}}$ & $762.6^{\text {abcd }}$ \\
\hline $50 \%$ Lupine $+100 \%$ f/millet & $1.27^{\mathrm{abc}}$ & $0.79^{d}$ & $-0.48^{d}$ & $2634.7^{\mathrm{ab}}$ \\
\hline $75 \%$ Lupine $+100 \%$ f/millet & $1.28^{\mathrm{ab}}$ & $0.78^{d}$ & $-0.19^{d}$ & $2425.0^{\mathrm{ab}}$ \\
\hline LSD (0.05) & 0.46 & 7.24 & 7.31 & 1935.29 \\
\hline
\end{tabular}

Notes: Values (means) connected by different superscript letters are significantly ( $<0.05$ ) different within columns according to Tukey- HSD tests. MAI was based on the lowest price of wheat (3 birr $/ \mathrm{kg})$, barley (2.8 birr $/ \mathrm{kg})$, f/millet (2.6 birr $/ \mathrm{kg}$ ) and lupine (3.11 birr $/ \mathrm{kg})$ at Adet market, West Gojam, Amhara region in June 2009-January 2010. MAI: monitory advantage index; CR: Competitive ratio, SD: Standard division and AARC: Adet Agricultural Research center. 


\subsubsection{Competitive Ratio (CR)}

Competitive ratio (CR) is only used as a measure of intercrop competition (inter-specific competition) [31]. CR of lupine, cereal and total were significantly $(\mathrm{P}<0.01)$ influenced by intercropping lupine with wheat, barley and finger millet in three seeding ratios. The results showed that intercropped lupine had higher competitive ratios in all proportions with finger millet, indicating that lupine was more competitive (CR > one) than finger millet (CR < one) (Table 4). However, in all other mixtures the values of CR for cereals (wheat and barley) were greater than for lupine indicating the dominance of cereals. This corroborates with [31], who stated that barley was dominant over lupine in intercrops on the sandy and sandy loam soil site. In most cases, the CR of wheat decreased, where as the CR of barely and finger millet increased as the proportion increased in the mixtures (Table 4). However, almost near to hundred percent CR value for barley was recorded in lupine-barely combination in descending order at 75:100 (27.90), 50:100 (20.27) and 25:100 (13.20) seeding ratios, which severely affected lupine agronomic characteristics. This could probably occur through lowering its abundance, for example through uptake of a growth limiting nutrient resource [32] or the creation of shade [33] or facilitating the growth of other crops by increasing the availability of the intermediary as is the case when symbiotically fixed nitrogen $(\mathrm{N})$ would be transferred from intercropped legumes to intercropped non-legumes [34]. This reversal in competitive ability along with the observation that early barley dominance did appear to suppress lupine growth indicates that differences in phenology did not played a role in shaping the prevailing dynamics. This result corroborates with [35], who reported that the competitive ratio of barley relative to pea showed that barley was most competitive at recommended plant density (CRBP $>$ one).

In contrary, intercropping lupine with finger millet in particular and wheat relatively gave higher cooperation and minimizes competition between them as compared to intercropped with barely. The common explanation given for this advantage was that the species make partially complementary use of growth resources, in either time or space, and thus use resources more efficiently with very low CR differences. The observations on competition indicators in the present study also corroborated the Crimes theory of competitive success in which the species with greater capacity for resource capture will be the superior competitor [36]. Accordingly, barley in particular and wheat in general was the superior competitor during the co-growth stage.

\section{Summery and Conclusion}

The combined yield advantage in terms of total LER was greater than one in the cases of lupine-wheat followed by lupine-finger millet mixtures at all seeding ratios. However, because of ATER provided more realistic comparison of the yield advantage, the lupine-finger millet mixture at the 50:100 and 75:100 seeding ratio, the lupine-wheat mixture at the 75:100 seeding ratio had a higher yield advantage of intercropping for exploiting the resources of the environment compared with the other intercropping systems, though they did not significantly different from each other. This also indicated that the area planted to monocultures would need $37.78 \%$, 37.19\%, and $31.3 \%$ more lands, respectively than the area planted to intercropping for the two crops to produce the same combined grain yield.

All lupine-wheat and lupine-finger millet intercropping systems at all seeding ratios were found to be the most profitable (higher MAI) as compared to the respective sole cropped and lupine-barley combinations. Lupine was dominated by wheat and barley in lupine-wheat and lupine-barely mixture at all seeding ratios, respectively.

More importantly, three of the best combinations which were differed from what farmers currently use ( $\leq 25 \%$ lupine seed rate with full cereal seed rate) include the lupine-finger millet mixtures at the 50:100 and 75:100 seeding ratio; and lupine-wheat mixture at the 75:100 seeding ratio indicated a significant advantage from intercropping, as elucidated in better MAI, land use efficiency (higher LER and ATER), lower CR than the other mixtures. These mixtures seem promising in the development of sustainable crop production with a limited use of external inputs.

\section{Research Needs}

From the present study, intercropping of lupine with wheat and finger millet in additive series in which cereals are the main crop component and lupine is the minor crop component seems better alternative to intensify productivity with a limited use of external inputs. Conversely, intercropping lupine with barley in the above system was considered to be too risky to cultivate (low yield reliability). However, for its effective realization, the fol- 
lowing valuable recommendations are also suggested: 1) Further research is essential to include the most widespread combinations; and evaluated under different agro-ecological zones, across seasons, different soil type's, different planting patterns (row intercropping, broadcast mixed cropping or strip intercropping), date of planting (simultaneous and relay, 2) Focus should be also given to the assessment of other socio-economic and cost of production aspects of intercropping especially under small scale farmers' conditions.

\section{References}

[1] Mitchell, C.E., Tilman, D. and Groth, J.V. (2002) Effects of Grassland Plant Species Diversity, Abundance, and Composition on Foliar Fungal Disease. Ecology, 83, 1713-1726. http://dx.doi.org/10.1890/0012-9658(2002)083[1713:EOGPSD]2.0.CO;2

[2] Hauggaard-Nielsen, H., Ambus, P. and Jensen, E.S. (2001) Interspecific Competition, N Use and Interference with Weeds in Pea-Barley Intercropping. Field Crop Research, 70, 101-109. http://dx.doi.org/10.1016/S0378-4290(01)00126-5

[3] Nigusei, T. (1994) Performance of Maize/Bean Intercropping Systems under Low and Medium Rainfall Situations, Unpublished M.Sc. Thesis, Alemaya University of Agriculture, Ethiopia.

[4] Amare, B. (1987) Maize-Soybeans Intercropping. 19th National Crop Improvement Conference, Adis Ababa, 22-26 April 1987.

[5] Jansen, P.C.M. (2006) Lupines albus L. In: Brink, M. and Belay, G., Eds., PROTA (Plant Resources of Tropical Africa) Wageningen. http://www3.interscience.wiley.com/journal/

[6] Central Statistical Agency (2012) Agricultural Sample Survey. 2011/2012 Volume I Report on Area and Production of Major Crops. Statistical Bulletin. May 2012, Addis Ababa.

[7] Aleligne, K. and Steven, F. (1987) Initial Results of Informal Survey Adet Farming System, Gojam Region, and Working Paper No.2187, IAR and Bair Dar, Ethiopia.

[8] Willey, R.W. and Osiru, D.S.O. (1972) Studies on Mixtures of Maize and Beans (Phaseolus vulgaris) with Particular Reference to Plant Population. Journal of Agricultural Science, 79, 517-529. http://dx.doi.org/10.1017/S0021859600025909

[9] Willey, R.W. and Rao, M.R. (1980) A Competitive Ratio for Quantifying Competition between Intercrops. Experimental Agriculture, 16, 117-125. http://dx.doi.org/10.1017/S0014479700010802

[10] Willey, R.W. (1979b) Intercropping-Its Importance and Research Needs. Part II. Agronomy and Research Approaches. Field Crop Abstract, 32, 73-85.

[11] AARC (Adet Agricultural Research Center) (2002) Summary of Research Achievements (1987-2001), Adet, Amhara, Ethiopia.

[12] Mead, R. and Willey, R.W. (1980) The Concept of Land Equivalent Ratio and Advantages in Yields from Intercropping. Experimental Agriculture, 16, 217-228. http://dx.doi.org/10.1017/S0014479700010978

[13] Ofori, F. and Stern, W.R. (1987) Cereal and Legume Intercropping Systems. Advanced Agronomy, 41, 41-90. http://dx.doi.org/10.1016/S0065-2113(08)60802-0

[14] Hiebsch, C.K. (1980) Principles of Intercropping. Effect of N Fertilization and Crop Duration on Equivalency Ratios in Intercrops versus Monoculture Comparisons. PhD thesis, North Carolina State University, Raleigh.

[15] Willey, R.W. (1979) Intercropping, Its Importance and Research Needs. Part 1. Competition and Yield Advantages. Agronomy and Research Approaches. Field Crop Abstract, 32, 1-10.

[16] YWARDO (Yilmana Denesa Wereda Agricultural and Rural Development Office) (2009) Annual Plan of Office of Agriculture and Natural Resources Development Adet, Amhara. (Unpublished)

[17] Ghosh, P.K. (2004) Growth, Yield, Competition and Economics of Groundnut/Cereal Fodder Intercropping Systems in the Semi-Arid Tropics of India. Field Crops Research, 88, 227-237. http://dx.doi.org/10.1016/j.fcr.2004.01.015

[18] SAS Institute Inc. (2002) JMP-5 Statistical Software, Version 5. Cary, USA.

[19] Beets, W.C. (1982) Multiple Cropping and Tropical Farming Systems. Gower, London, Britain, and West Views Press, Colorado.

[20] Caballero, R., Goicoechea, E.L. and Hernaiz, P.J. (1995) Forage Yields and Quality of Common Vetch and Oat Sown at Varying Seeding Ratios and Seeding Rates of Common Vetch. Field Crop Research, 41, 135-140. http://dx.doi.org/10.1016/0378-4290(94)00114-R

[21] Yadav, R.S. and Yadav, O.P. (2001) The Performance of Cultivars of Pearl Millet and Cluster Bean under Sole Cropping and Intercropping Systems in Arid Zone Conditions in India. Experimental Agriculture, 37, 231-240.

http://dx.doi.org/10.1017/S0014479701002046 
[22] Aasim, M., Muhammad, E.U. and Karim, A. (2008) Yield and Competition Indices of Intercropping Cotton (Gossypium hirsutum L.) Using Different Planting Patterns. Ankara.

[23] Reddy, K.C., Visser, P.L., Klaij, M.C. and Renard, C. (1994) The Effects of Sole and Traditional Intercropping of Millet and Cowpea on Soil and Crop Productivity. Experimental Agriculture, 30, 83-88. http://dx.doi.org/10.1017/S0014479700023875

[24] Chen, C., Westcott, M., Neill, K., Wichman, D. and Knox, M. (2004) Row Configuration and Nitrogen Application for Barley-Pea Intercropping in Montana. Journal of Agronomy, 96, 1730-1738. http://dx.doi.org/10.2134/agronj2004.1730

[25] Trydemanknudsen, M., Hauggaard-Nielsen, H., Jornsgard, B. and Steenjensen, E. (2004) Comparison of Inter-Specific Competition and N Use in Pea-Barley, Faba Bean-Barley, and Lupine-Barley Intercrops Grown at Two Temperate Locations. Journal of Agricultural Science, 142, 617-627. http://dx.doi.org/10.1017/S0021859604004745

[26] Banik, P., Samsal, T., Ghosal, P.K. and Bagchi, D.K. (2000) Evaluation of Mustard and Legume Intercropping under 1:1 and 1:2 Row Replacement Series System. Journal of Agronomy and Crop Science, 185, 9-14. http://dx.doi.org/10.1046/j.1439-037X.2000.00388.x

[27] Tamado, T. and Eshetu, M. (2000) Evolution of Sorghum, Maize and Common Bean Cropping Systems in East Harerghe, Eastern Ethiopia. Journal of Agricultural Science, 17, 33-45.

[28] Bhadoria, R.B., Chauhan, G.S., Kushwaha, H.S. and Singh, V.N. (1992) Intercropping of Cluster Bean and Pearl Millet. Indian Journal Agronomy, 17, 416-439.

[29] Dutta, H.S., Baroova, S.R. and Rajkhowa, D.J. (1994) Feasibility and Economic Profitability of wheat (Triticum aestivum)-Based Intercropping System under Rain Fed Conditions. Indian Journal of Agronomy, 39, 448-450.

[30] Dhima, K.V., Lithourgidis, A.S. and Dordas, C.A. (2006) Competition Indices of Common Vetch and Cereal Intercrops in Two Seeding Ratio. Field Crops Research, 100, 249-256. http://dx.doi.org/10.1016/j.fcr.2006.07.008

[31] Trydeman, K.M., Hauggaard-Nielsen, H., Jornsgard, B. and Steen, J.E. (2004) Comparison of Interspecific Competition and N Use in Pea-Barley, Faba Bean-Barley and Lupine-Barley Intercrops Grown at Two Temperate Locations. Journal of Agricultural Science, 142, 617-627. http://dx.doi.org/10.1017/s0021859604004745

[32] Zhang, F. and Li, L. (2003) Using Competitive and Facilitative Interactions in Intercropping Systems Enhances Crop Productivity and Nutrient-Use Efficiency. Plant and Soil, 248, 305-312. http://dx.doi.org/10.1023/A:1022352229863

[33] Berntsen, J., Hauggaard-Nielsen, H., Olesen, J.E., Petersen, B.M., Jensen, E.S. and Thomsen, A. (2004) Modeling Dry Matter Production and Resource Use in Intercrops of Pea and Barley. Field Crops Research, 88, 69-83. http://dx.doi.org/10.1016/j.fcr.2003.11.012

[34] Jensen, E.S. (1996) Grain Yield, Symbiotic N-2 Fixation and Interspecific Competition for Inorganic N in Pea-Barley Intercrops. Plant Soil, 182, 25-38. http://dx.doi.org/10.1007/bf00010992

[35] Hauggaard-Nielsen, H., Mette Klindt, A., Bjarne, J. and Erik Steen, J. (2005) Density and Relative Frequency Effects on Competitive Interactions and Resource Use in Pea-Barley Intercrops. Field Crop Research, 95, 256-267. http://orgprints.org/4053/

[36] Grace, J. (1990) On the Relationship between Plant Traits and Competitive Ability. In: Grace, J.B. and Tilman, D., Eds., Perspective on Plant Competition, Academic Press, San Diego, 51-65. 